\title{
RETRO-CORNEAL HYALINE BANDS IN INTERSTITIAL KERATITIS*
}

\author{
BY \\ J. SWARTZ \\ London
}

RETRO-CORNEAL hyaline bands may occur as congenital abnormalities or as a result of compression of the globe following birth trauma, and they are not uncommon in longstanding cases of iridocyclitis due chiefly to syphilis 0 or tuberculosis. Lehmann (1927) in a comprehensive review of 103 cases of interstitial keratitis, stated that 17.5 per cent. cases showed these bands; in 88 there was definitely congenital or acquired syphilis, and the remaining ten had tuberculosis.

The bands were demonstrable only in the first eye to be affected. They were caused by a rupture of Descemet's membrane because of deep infiltration of the cornea, by the formation of folds after the recession of the corneal swelling, or by a deposition of fibrin on the back of the cornea as a result $\frac{\mathrm{D}}{\mathrm{D}}$ of exudation from the iris.

\section{Case Report}

A married woman aged 27 has been under observation since the age of 12 years. She first attended in 1937 with an inflamed left eye and subsequent inflammation of the right $\frac{0}{0}$ eye. A diagnosis of interstitial keratitis was made and she was admitted for a course of $\frac{0}{3}$ anti-specific treatment. The serological reaction in 1937 was Wassermann reaction,$++ \stackrel{3}{\circ}$ Kahn test positive. These tests were negative in 1952. The inflammation in the right eye $\frac{0}{3}$ recurred in 1945 and 1952.

Past History.- In 1942, she was an in-patient for 12 months in a sanatorium for tubercu- $\frac{\circ}{J}$ losis of the left lung. She had a phrenic crush and artificial pneumothorax. She was $\frac{7}{0}$ re-admitted in 1945 for a right phrenic crush and artificial pneumothorax. Her lung condition is now considered cured.

\section{Examination.}

Right Eye.-Slight ciliary flush. Extensive deep vascularization of cornea with vessels encroaching all round limbus and passing to centre of cornea. Numerous keratic precipitates and hazy appearance of endothelium.

Diamond-shaped fibrin bands projecting into anterior chamber deep to the cornea, but adherent $\cong$ to the cornea at their extremities (Figure). Descemet's membrane intact. A few keratic precipitates deposited on the fibrin bands: flare and cells in the anterior chamber. Small areas of old o choroido-retinitis scattered throughout the periphery of the fundus. The visual acuity was $6 / 36$ in the right eye without glasses, $6 / 12$ with correction. 


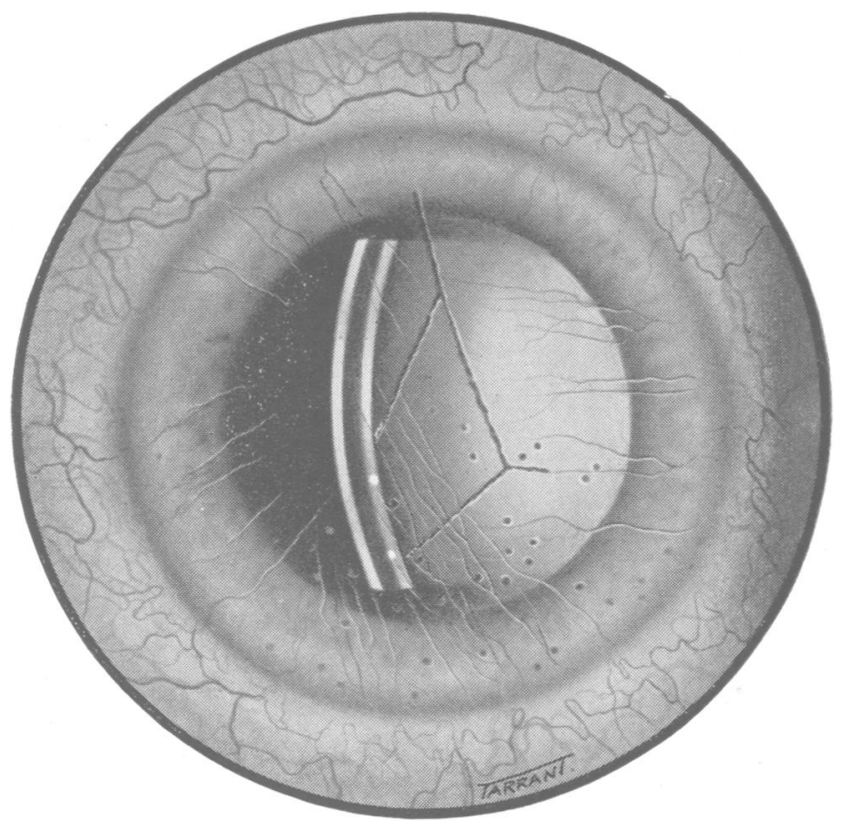

Figure.

Left Eye.-White. Mottled appearance of corneal endothelium. No signs of active iridocyclitis. Extensive area of old choroido-retinitis in lower half of fundus. Visual acuityl in the left eye $6 / 24$ without glasses, $6 / 12$ with correction.

In this case Descemet's membrane was intact and the bands resulted from fibrin deposition in the anterior chamber.

My thanks are due to Mr. Eugene Wolff for permission to publish this case and for help in preparing it for the press.

\section{REFERENCES}

Lehmann, H. (1927). Z. Augenheilk., 62, 230.

TREVOR-ROPER, P. D. (1949). British Journal of Ophthalmology, 33, 635. 